Highlights

\title{
Impact of Mileage on Particle Number Emission Factors for EURO5 and EURO6 Diesel Passenger
} Cars

François Boveroux,Séverine Cassiers,Philippe De Meyer,Pascal Buekenhoudt,Benjamin Bergmans,François Idczak,Hervé Jeanmart,Sebastian Verhelst,Francesco Contino

- Particle number measurements on 757 diesel passenger cars from the field, homologated according to the EURO5 and EURO6 emission standards.

- Fleet average emission factors are strongly increased due to the presence of high emitters.

- The Handbook Emission Factors for Road Transport strongly underestimate the particle number emission factors of the tested fleet.

- Mileage has a significant impact on the particle number emissions. 


\title{
Impact of Mileage on Particle Number Emission Factors for EURO5 and EURO6 Diesel Passenger Cars
}

\author{
François Boveroux ${ }^{a, b}$, Séverine Cassiers ${ }^{a, b}$, Philippe De Meyer ${ }^{c}$, Pascal Buekenhoudt ${ }^{c}$, \\ Benjamin Bergmans ${ }^{d}$, François Idczak ${ }^{d}$, Hervé Jeanmart ${ }^{e}$, Sebastian Verhelst ${ }^{f, g}$ and \\ Francesco Contino $^{e}$ \\ ${ }^{a}$ Vrije Universiteit Brussel (VUB), Thermo and Fluid dynamics (FLOW), Brussels, Belgium \\ ${ }^{b}$ Vrije Universiteit Brussel (VUB) and Université Libre de Bruxelles (ULB), Combustion and Robust Optimization Group (BURN), Brussels, Belgium \\ ${ }^{c}$ GOCA Vlaanderen vzw, Brussels, Belgium \\ ${ }^{d}$ Cellule Emissions Atmosphériques, Institut Scientifique de Service Public (ISSeP), Liège, Belgium \\ ${ }^{e} i M M C$ - Institute of Mechanics, Materials and Civil Engineering, Université catholique de Louvain, Louvain-la-Neuve, Belgium \\ ${ }^{f}$ Department of Electrical Energy, Metals, Mechanical Constructions and Systems, Ghent University, Belgium \\ ${ }^{g}$ Department of Energy Sciences, Lund University, Sweden
}

\section{ARTICLE INFO}

\section{Keywords:}

Particulate matter

Particle number

Degradation

Diesel Particulate Filter

Emission factor

Emission model

\begin{abstract}
A B S TR ACT
Air quality is a growing concern worldwide because of its impacts on both the environment and the human health. The road transport sector is a major contributor to this poor air quality. To reduce the emission of particulate matter, all diesel passenger cars were equipped with diesel particulate filters since the EURO5b emission standard. Unfortunately, these filters can be damaged or intentionally removed during the lifetime of a vehicle. This work presents the particle number emission factors for EURO5 and EURO6 diesel passenger cars, based on the measurements of 757 vehicles. These measurements were performed at low idle, which shows a high correlation to particle number emission factors obtained during homologation cycles or real-driving emission measurements. The results show that the average Particle Number (PN) emission factors are highly impacted by high emitters present in the fleet and that the mileage has a significant impact on the PN emission factors. Finally, the estimated PN emission factors based on low idle measurements were higher by a factor 5.6 for EURO5a, 2.5 for EURO5b and 5.5 for EURO6, compared to their respective HBEFA (Handbook Emission Factors for Road Transport) emission factors.
\end{abstract}

\section{Introduction}

Air quality is a major environmental and health issue in

many places over the world. In Europe, air quality limit values have been defined for $\mathrm{PM}_{2.5}$ and $\mathrm{PM}_{10}$ (particulate matter with a diameter smaller than 2.5 and $10 \mu \mathrm{m}$, respectively): the $\mathrm{PM}_{2.5}$ yearly average must not exceed $25 \mu \mathrm{g} / \mathrm{m}^{3}$ while $\mathrm{PM}_{10}$ values must respect a yearly average of $40 \mu \mathrm{g} / \mathrm{m}^{3}$ and a 24-hour average of $50 \mu \mathrm{g} / \mathrm{m}^{3}$ (this 24-hour average can be exceeded 35 times per year). In 2016, the yearly $\mathrm{PM}_{2.5}$ limit was not respected at $5 \%$ of the European reporting stations while the $\mathrm{PM}_{10}$ daily limit was exceeded at $19 \%$ of these stations. Also in 2016, long-term exposure to $\mathrm{PM}_{2.5}$ caused 422000 premature deaths in Europe [9].

Additionnally to these EU limits, the World Health Organization (WHO) defined Air Quality Guidelines (AQG) which are more strict than the current EU limits. These guidelines recommend that $\mathrm{PM}_{2.5}$ remains below $10 \mu \mathrm{g} / \mathrm{m}^{3}$ for the annual average and below $25 \mu \mathrm{g} / \mathrm{m}^{3}$ for the 24 -hour average. Regarding $\mathrm{PM}_{10}$, the guidelines are $20 \mu \mathrm{g} / \mathrm{m}^{3}$ for the annual mean and $50 \mu \mathrm{g} / \mathrm{m}^{3}$ for the daily mean. These more stringent yearly values were exceeded at $68 \%$ of the European reporting stations for the $\mathrm{PM}_{2.5}$ and at $48 \%$ of the

\footnotetext{
*Corresponding author

(1) francesco.contino@uclouvain.be, Phone +32 104722 05, Fax +32 104526 92, Place du Levant 2/L5.04.03, 1348 Louvain-la-Neuve, Belgium (F. Contino)

ORCID(s):
}

stations for $\mathrm{PM}_{10}$ [9]. These air quality issues are even more severe in urban areas as between 74 and $85 \%$ of urban populations in the EU-28 are exposed to yearly $\mathrm{PM}_{2.5}$ concentrations above the WHO AQG since 2014.

Regarding the ultrafine particles (particulate matter with a diameter smaller than $0.1 \mu \mathrm{m}$ ), there is still a knowledge gap regarding their impact on human health which explains the absence of air quality guidelines for this type of pollutant [13]. Ultrafine particles may be more harmful than $\mathrm{PM}_{2.5}$ and $\mathrm{PM}_{10}$ because their smaller sizes allow them to penetrate deeper inside the respiratory system and to translocate to different organs [13].

The road transport sector is a major contributor to this poor air quality as it accounted for $11 \%$ of $\mathrm{PM}_{2.5}$ and for $10 \%$ of $\mathrm{PM}_{10}$ in 2016 for the EU-28 countries [9]. Regarding the ultrafine particles, the road transport was responsible for around 40\% of the total emissions in Europe in 2010 [15].

Emission models, such as HBEFA (Handbook Emission Factors for Road Transport) or COPERT (COmputer Programme to calculate Emissions from Road Transport), are used by public authorities to estimate the emissions of the road transport sector. They use as inputs: environmental data, fleet caracteristics and activity data. Based on the model parameters such as the Emission Factors (EFs) (amount of pollutant emitted per travelled kilometer) and the degradation factors (to account for deterioration of emissions with mileage), the model estimates the emissions of this specific 
fleet. These emission models are used to compute the emission inventories for a city, a region or a country. They are also useful to assess the potential impact of mobility policies such as Low Emission Zones progressively banning the most polluting vehicles.

The accuracy of these model outputs is largely affected by uncertain model parameters and model inputs. The major uncertainty source comes from the EFs used in this model [18]. Initially these EFs were only based on laboratory tests but now they also include real-world results such as remote sensing or real driving testing using a Portable Emissions Measurement System (PEMS). Real driving emission measurements provide very accurate results for a limited number of vehicles but are very expensive and time consuming.

A major drawback of these emission models is that they use averages for all the inputs and model parameters. Because their average value is considered, they fail to a great extend to represent the very large variability of local pollutants because these pollutant emissions are extremely nonlinear. Several studies also show that the real-world emissions are non-linearly spread from below homologation values up to more than a factor 10 above $[3,6]$. Instead of using averages, these models could use probability distributions for their inputs and model parameters to better represent their wide spread and take into account the non-linearities of Particle Number (PN) emissions. The usage of averages is usually motivated by the lower computational cost which is required compared to using distributions. Nevertheless, the curse of dimensionality generally limit the application of uncertainty in complex systems. Recent techniques take advantage of the sparsity of such systems to significantly reduce the computational cost (up to 10 times) of uncertainty propagation [1]. Including uncertainties, in particular for highly non-linear pollutants, would improve the predictions and better guide policy makers.

Previous studies [17, 4] proved that actual fleet emissions can be highly affected by high emitters. In the case of particulate matter for diesel vehicles, Diesel Particulate Filter (DPF) became standard since the EURO5a emission standard in 2009 and became mandatory since the EURO5b emission standard in 2011, in order to lower their emissions. Unfortunately, high emitters among those recent diesel vehicles can be explained by damaged or voluntarily removed DPFs. Because current Periodic Technical Inspection (PTI) cannot detect such high emitters of particulate matter, their DPFs are not repaired or replaced and the contribution of these high emitters could increase the average fleet emissions by a factor 30 [4].

In this context, recent studies were conducted in Belgium, Germany, the Netherlands and Switzerland to assess the possibility of implementing a new test procedure to detect these high emitters of particulate matter emissions. We developed a test procedure which consists of measuring the PN from a diameter of $23 \mathrm{~nm}$ and above, such as for the homologation but instead of following a cycle as during the homologation, the test would be performed at low idle. While not replacing costly and time consuming homologation tests, low idle PN measurements show high correlation with their results [8]. This new procedure will be implemented in Belgium as of 2021 while Germany and Netherlands should implement a similar procedure in 2021.

This paper first explains the measurement procedure, the data collected during its development (i.e. particulate matter concentration of 757 EURO5 and EURO6 diesel passenger cars during a low idle test) and the measurement devices. Then, the correlation between PN concentrations measured at low idle and PN emission factors is discussed. Finally, the computed PN emission factors are provided for the tested vehicles from the actual fleet together with an analysis of influencing factors such as the emission standard and the mileage of the vehicles. Using this large database, this paper extends the current use of PN emission factor averages to distributions to be used in emission models, taking into account the small fraction of high emitting vehicles having a major impact on the fleet average. Ultimately, the goal of this paper is to provide a better characterization of the emissions of these EURO5 and EURO6 diesel vehicles since they are becoming the only diesel vehicles allowed in many Low Emission Zones implemented across the world.

\section{Methodology}

\subsection{Test procedure and measurement devices}

In a previous study, we developed a test methodology for the PTI to detect removed and damaged DPF [4]. This test consists of measuring the PN emissions of a vehicle during a low idle test: gearbox in neutral position, engine warmed up and at low idle speed (i.e. without depressing the accelerator pedal). The PN value (in $\# / \mathrm{cm}^{3}$ ) is the result of 3 measurements of 5 seconds each.

We analysed the efficacy of three different PN measurement devices: the TSI NPET, the Pegasor Mi3 and the Testo NanoMet3. These devices are already commercially available and are typically used for automotive applications (see Table 1). The PN measurements were performed on every EURO5 and EURO6 diesel passenger car using one of the 3 previously mentioned PN measurement devices. These measurements were executed just after the opacity test which is currently the only emission related test at the PTI for this type of vehicles in Europe. The tests were performed either by us or by the employees of different accredited PTI companies across Belgium.

These 3 devices were compared on 68 vehicles before being sent individually to PTI stations. These comparative measurements were performed by introducing simultaneously in the exhaust pipe the probe of the TSI device and the one of either the Pegasor or the Testo. The results of the comparison showed a high correlation between the studied devices. Some differences could be observed between the devices and could be explained by the different measurement principles (i.e. condensation particulate counting or diffusing charging), the dilution ratio or the accuracy of the cut-off value for the small particles (i.e. $23 \mathrm{~nm}$ ). These differences will be taken into account in the uncertainty of the results by 
Impact of Mileage on Particle Number Emission Factors for EURO5 and EURO6 Diesel Passenger Cars

\begin{tabular}{|c|c|c|c|}
\hline Brand & TSI & Pegasor & Testo \\
\hline Model & NPET & Mi3 & NanoMet3 \\
\hline Technology & $\begin{array}{c}\text { Condensation } \\
\text { Particle } \\
\text { Counting }\end{array}$ & $\begin{array}{c}\text { Diffusion } \\
\text { Charging }\end{array}$ & $\begin{array}{c}\text { Diffusion } \\
\text { Charging }\end{array}$ \\
\hline $\begin{array}{c}\text { Measured } \\
\text { sizes }\end{array}$ & $\begin{array}{c}23 \mathrm{~nm} \\
\text { to } 1 \mu \mathrm{m}\end{array}$ & $\begin{array}{c}23 \mathrm{~nm} \\
\text { to } 2.5 \mu \mathrm{m}\end{array}$ & $\begin{array}{c}23 \mathrm{~nm} \\
\text { to } 700 \mathrm{~nm}\end{array}$ \\
\hline $\begin{array}{c}\text { Measurement } \\
\text { range [\#/cm }{ }^{3} \text { ] }\end{array}$ & 1000 to $5 \mathrm{e} 6$ & 600 to $1.3 \mathrm{e} 9$ & $1 \mathrm{e} 4$ to $3 \mathrm{e} 8$ \\
\hline $\begin{array}{c}\text { Removed } \\
\text { volatiles }\end{array}$ & $\begin{array}{c}\text { Catalytic } \\
\text { Stripper } \\
\left(350^{\circ} \mathrm{C}\right)\end{array}$ & $\begin{array}{c}\text { Heated } \\
\text { Sample Line } \\
\left(200^{\circ} \mathrm{C}\right)\end{array}$ & $\begin{array}{c}\text { Heated } \\
\text { Sample Line } \\
\left(100^{\circ} \mathrm{C}\right) \\
\text { \& Evaporation } \\
\text { Tube }\left(300^{\circ} \mathrm{C}\right)\end{array}$ \\
\hline Dilution & $10: 1$ & No & $\begin{array}{c}\text { Variable } \\
(10: 1 \text { up to } \\
300: 1)\end{array}$ \\
\hline
\end{tabular}

Table 1

Main technical characteristics of the 3 PN measurement devices.

integrating the prediction error of the correlation into the PN EF calculations. Indeed, the uncertainty of these PN measurement devices is typically below $50 \%$ [5], which is significantly below the correlation uncertainty (factor between 3 and 4, see section 2.2). An example of a time series data comparing the TSI NPET and the Pegasor Mi3 is provided in Figure 1, which also shows the stabilization time of these 2 devices when inserting the probe in the exhaust pipe.

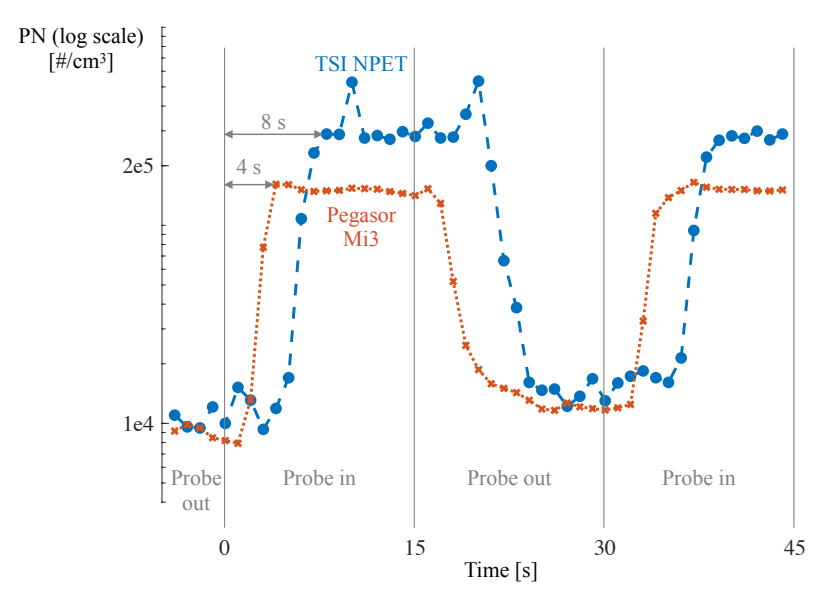

Figure 1: "Probe in" and "Probe out" correspond to the periods during which the probe was measuring inside the exhaust pipe and in the ambient air, respectively. The Pegasor Mi3 is the quickest device with a transformation time between 4 and 6 seconds, while the TSI NPET needs between 7 and 9 seconds to reach stable values.

The TSI NPET and the Testo NanoMet 3 were also compared to a AVL M.O.V.E PN PEMS iS device, fulfilling the Real Driving Emission requirements (see Figure 2). The results show a high correlation between this Real Driving Emissions (RDE) compliant device and these 2 devices used to measure PN at low idle at the PTI.

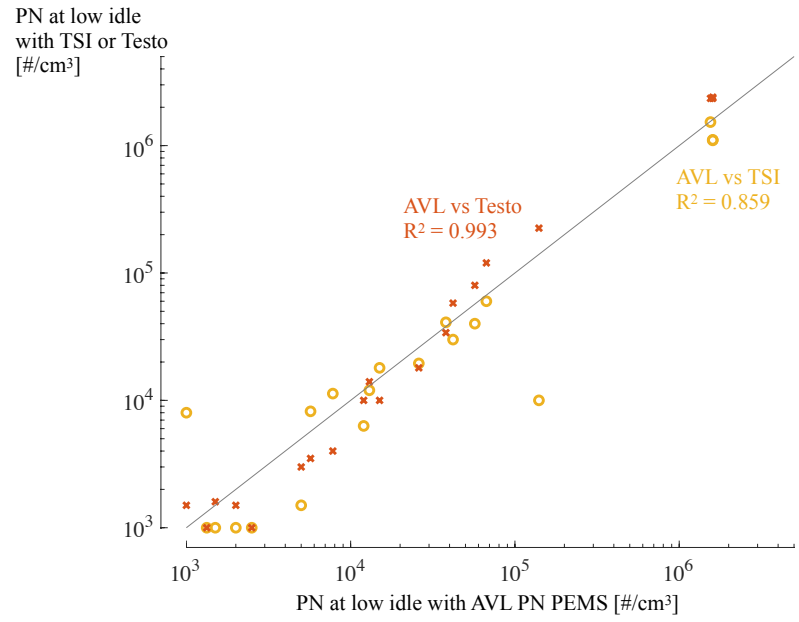

Figure 2: These comparative measurements show that the TSI NPET and the Pegasor Mi3 provide similar results compared the AVL PN PEMS, fulfilling the RDE requirements.

\subsection{Determining the $\mathbf{P N}$ emission factor}

The $\mathrm{PN}$ value measured at low idle $\left(\mathrm{PN}_{\text {low idle }}\right.$, expressed in $\# / \mathrm{cm}^{3}$ ) is correlated to the PN emission factor (PN EF, expressed in \#/km) that would be obtained during laboratory test cycles such as the NEDC or the WLTC (see Figure 3). On this Figure, each point represents the test of one vehicle, which includes the PN at low idle test and the PN EF measured during a test. These two driving cycles allow to test the vehicles at different speeds and vehicles loads. To establish this correlation, we combined emission measurements performed during a low idle test and during an homologation cycle. This data comes from the JRC [8] and from TNO [10]. The high emitting vehicles were obtained by removing the DPF or by intentionnaly reducing its filtration efficiency. The idea of a correlation between low idle and cycle results were introduced in several publications of TNO and the JRC $[8,10]$. There is no proof of causality but this correlation was shown as valid for many tests. Its principle is based on 


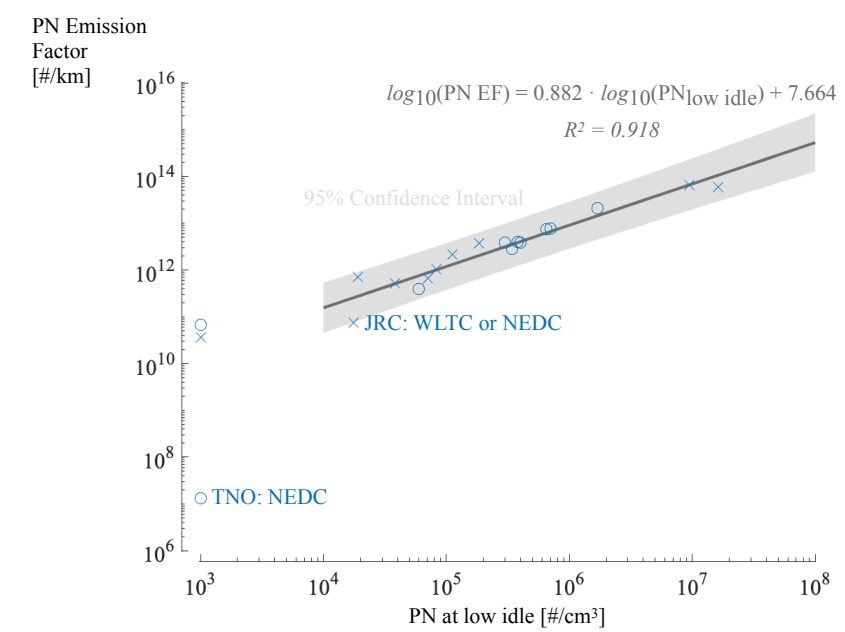

Figure 3: The PN EF for EURO5 and EURO6 diesel vehicles, that would be measured during NEDC or WLTC homologation cycle, can be estimated by a PN measurement at low idle. TNO data from [10] and JRC data from [8].

Thanks to the correlation between the PN low idle test $\left(\# / \mathrm{cm}^{3}\right)$ and the PN EF $(\# / \mathrm{km})$, the PN at low idle value of each tested vehicle will be converted into PN EFs using the

\footnotetext{
${ }^{1} 15$ degrees of freedom because $17 \mathrm{x}$-y coordinates were used for the regression minus 2 degrees of freedom that were lost to estimate the slope and the $y$-intercept of the regression
}

following equation:

$$
\begin{gathered}
\log _{10}(\mathrm{PN} \mathrm{EF})=0.882 \cdot \log _{10}\left(\mathrm{PN}_{\text {low idle }}\right)+7.664 \\
\text { for } 10000<\mathrm{PN}_{\text {low idle }}<8.4 \times 10^{6} \# / \mathrm{cm}^{3} .
\end{gathered}
$$

From these measurements PN at low idle test converted into PN EF, we have built an EF distribution for each emission standard, i.e. EURO5a, EURO5b and EURO6 diesel passenger cars. These distributions have also been further split by mileage categories, to analyse the degradation of emission performances of the fleet due to this factor.

\section{Results and discussion}

\subsection{Measurements from the PTI}

During this measurement campaign, 757 diesel passenger cars were measured, among which 629 are homologated according to the EURO5 emission standard (368 EURO5a and 261 EURO5b) and 128 according to EURO6. The split between EURO5a and EURO5b is due to the fact that the DPF was standard since the EURO5a emission regulations but became mandatory with the introduction of the EURO5b because of its limit on the PN emissions. The low amount of EURO6 vehicles can be explained by the more recent introduction of this emission standard, in 2014 for new type approval, and by the fact that vehicles usually undergo their first vehicle inspection after 4 years. The tested vehicles that are younger than 4 years either came because they are obliged to pass the PTI before being sold or because they are used professionnally to transport people (e.g. taxis), in which case the PTI needs to be performed every 6 months. The mileage and age distribution of the tested EURO5a, EURO5b and EURO6 vehicles are provided in Tables 2, 3 and 4, respectively.

The PN at low idle values of these 757 EURO5 and EURO6 ${ }_{240}$ vehicles, measured by ourselves or by the employees of the ${ }_{250}$ PTI, are provided in Figure 4. This figure shows these mea- ${ }_{251}^{251}$ surement values as a Cumulative Distribution Function (CDF) 252 to better understand what proportion of the fleet is below or ${ }_{253}^{253}$ above certain values. It shows that $53 \%$ of the vehicles have emissions below $5000 \# / \mathrm{cm}^{3}$, which corresponds to the PN concentration that is typically observed in ambient air at the different PTI stations. Also, 65\% of the vehicles have emissions below $10000 \# / \mathrm{cm}^{3}$ which corresponds to the lower range of the Testo NanoMet3 and to the lower limit for the validity of the correlation between the PN at low idle and the PN EF. Finally, this figure also shows that $15 \%$ of the vehicles have PN emissions above $250000 \# / \mathrm{cm}^{3}$ which is expected to be the future threshold to pass the test that will be implemented at the PTI in the coming years. This Figure also provides this information per EURO class.

\subsection{PN emission factors distributions}

Thanks to the existing correlation between the PN values measured at low idle and the PN EF (see Equation 1), the PN EF for each vehicle can be computed and then, using these individual PN EF values, the experimental CDF of 
Impact of Mileage on Particle Number Emission Factors for EURO5 and EURO6 Diesel Passenger Cars

\begin{tabular}{|c||c|c|c|c||c|}
\hline \multicolumn{1}{|c||}{$\begin{array}{c}\text { Age } \\
\text { [years] }\end{array}$} & $0-50$ & $50-100$ & $100-150$ & $>150$ & \\
\hline \hline $5-6.5$ & 3 & 22 & 30 & 19 & 74 \\
\hline $6.5-8$ & 11 & 58 & 79 & 64 & 212 \\
\hline $8-10$ & 7 & 13 & 22 & 40 & 82 \\
\hline Total & 21 & 93 & 131 & 123 & 368 \\
\hline
\end{tabular}

Table 2

Mileage and age distribution for EURO5a vehicles.

\begin{tabular}{|c|c|c|c|c|c|}
\hline \multirow{2}{*}{$\begin{array}{c}\text { Age } \\
\text { [years] }\end{array}$} & \multicolumn{4}{|c|}{ Mileage [thousands of km] } & \multirow[t]{2}{*}{ Total } \\
\hline & $0-50$ & $50-100$ & $100-150$ & $>150$ & \\
\hline $2-4$ & 17 & 65 & 20 & 7 & 109 \\
\hline $4-6$ & 8 & 54 & 48 & 27 & 137 \\
\hline $6-8.5$ & 0 & 4 & 5 & 6 & 15 \\
\hline Total & 25 & 123 & 73 & 40 & 261 \\
\hline
\end{tabular}

Table 3

Mileage and age distribution for EURO5b vehicles.

the tested fleet can be obtained (see Figure 5). The bands around the experimental CDF correspond to the $95 \%$ confidence interval and combines 2 effects. Firstly, the prediction error when converting the PN at low idle into the PN EF which is assumed to follow a t-student distribution with 15 degrees of freedom. Secondly, the bootstrapping method is used to take into account the effects of the limited sample size as well as the influence of the selection of the samples among the entire population [2]. Since the regression was computed with the PN at low idle values above $10000 \# / \mathrm{cm}^{3}$, only the PN EF greater than the value corresponding to this lower limit, i.e. $1.559 \times 10^{11} \# / \mathrm{km}$, were considered. The PN EF below this limit represent the cleanest vehicles of the fleet and although they fortunately represent $65 \%$ of the vehicles, they only represent $0.8 \%$ of the PN emissions of the tested fleet. In general, the EURO6 vehicles that were tested have a lower PN EF than the EURO5 vehicles: 89\% (confidence interval between $85 \%$ and $94 \%$ ) of the EURO6 vehicles have PN emission factors below the homologation limit (official limit when a vehicle is homologated according to the EURO5b or EURO6 emission standard, i.e. $6 \times 10^{11} \# / \mathrm{km}$ ) while only $85 \%$ (confidence interval between $79 \%$ and $88 \%$ ) of the EURO5b vehicles and 68\% (confidence interval between $63 \%$ and $73 \%$ ) of the EURO5a vehicles are below this limit, assuming the correlation mentioned above.

On top of the experimental CDF of the EURO5a and EURO5b vehicles, the CDF of the lognormal distribution fitted to the data, using the Maximum Likelihood Estimation method, is also provided (see Figures 6 and 7). The lognormal distribution has the following probability density function, where $\mu$ is the mean and $\sigma$ is the standard deviation:

$$
f(x)=\frac{1}{x \sigma \sqrt{2 \pi}} \exp \left(\frac{-(\ln x-\mu)^{2}}{2 \sigma^{2}}\right) .
$$

The lognormal distribution is particularly well suited to represent actual fleet emissions, because it can only consider positive values. Also, it is skewed with higher probabilities

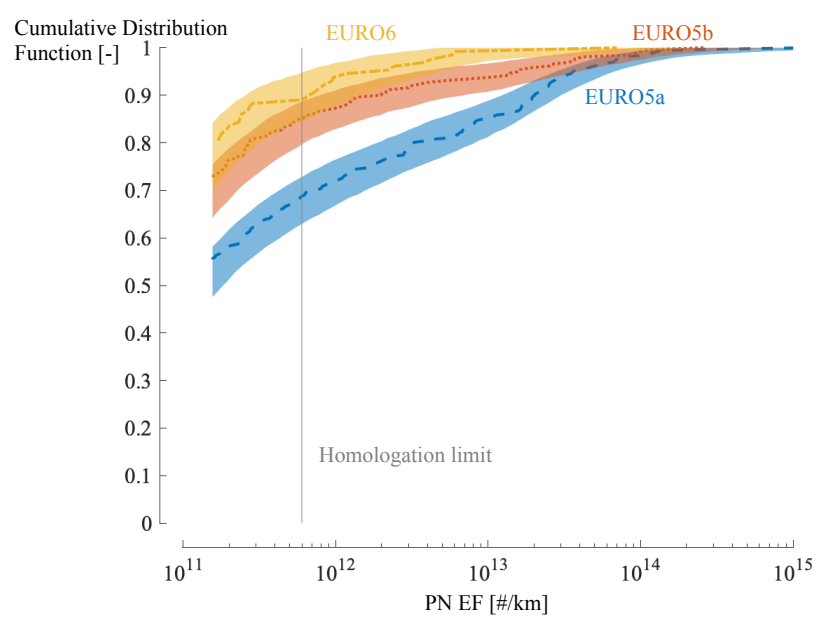

Figure 5: Experimental cumulative distribution functions of the computed PN EF (\#/km) for the EURO5a, EURO5b and EURO6 diesel passenger cars and their $95 \%$ confidence intervals.

for values lower than the average but with a long tail for the high values representing the high emitters [12]. Additionally, 3 important PN EF are shown: the experimental arithmetic average of the PN EF, the homologation limit (i.e. $6 \times$ $10^{11} \# / \mathrm{km}$ ) and the arithmetic average HBEFA (Handbook Emission Factors for Road Transport) value. For EURO5a, there is no homologation limit so the value is indicative, while the HBEFA does not make any difference between EURO5a and EURO5b. The HBEFA provides emission factors for the $\mathrm{CO}_{2}$ emission, for the regulated pollutants but also for some unregulated pollutants. These emission factors are available for a wide range of vehicles categories, fuels and EURO standards and consider different driving conditions (urban, rural and highway) [11]. Initially, these HBEFA emission factors were mainly based on measurements from homologation cycles but now they include more 
and more real-driving emission measurements with PEMS or Remote Sensing to better represent the reality. The HBEFA emission factors are commonly used for emission inventories to assess the emissions of the road transport sector.

In the case of EURO5a and EURO5b vehicles, the average HBEFA emission factor (arithmetic average of the urban, rural and highway emission factors based on equal distance shares, similar to the RDE regulations) equals $1.04 \times$ $10^{12} \# / \mathrm{km}$ and is only slightly higher than the homologation figure, i.e. $6 \times 10^{11} \# / \mathrm{km}$ (see Table 5). Assuming the previously mentioned correlation, the experimental arithmetic average based on the 368 EURO5a tested vehicles shows that the high emitters have a significant impact on the fleet arithmetic average emission factor, i.e. $5.79 \times 10^{12} \# / \mathrm{km}$. Therefore, the homologation (not applicable for EURO5a) and the HBEFA figures are lower than the calculated fleet emissions (estimated based on low idle measurement and the correlation) for EURO5a by a factor 9.6 and 5.6, respectively. For the 261 EURO5b vehicles, the fleet arithmetic average emission factor equals $2.60 \times 10^{12} \# / \mathrm{km}$, which is higher by a factor 4.3 than to the homologation limit and by a factor 2.5 than the HBEFA figures. It should be highlighted that the homologation limit needs to be fulfilled for a specific driving cycle and under well defined conditions, which can explain the discrepancies with real-world driving and with the estimated PN EF.

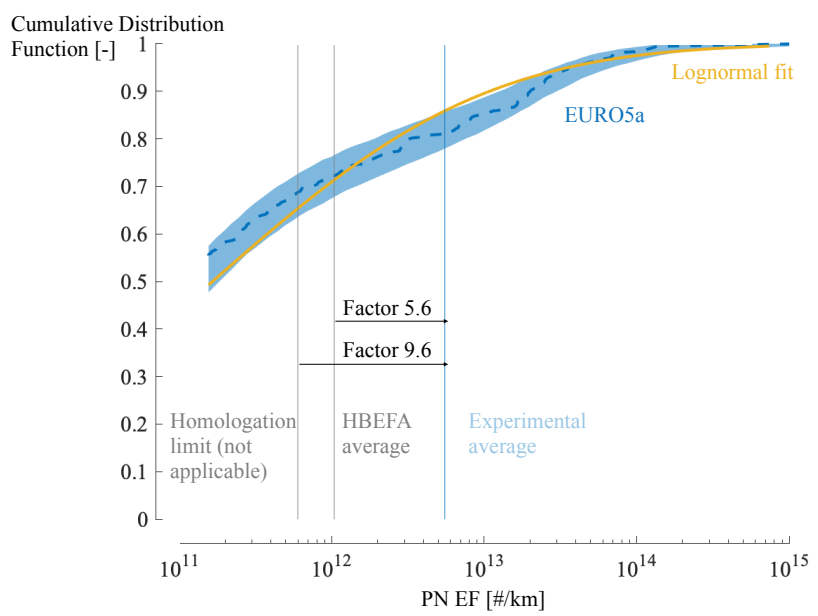

Figure 6: Cumulative distribution function of the computed PN EF $(\# / \mathrm{km})$ for the EURO5a diesel passenger cars. Lognormal fit parameters: $\mu=25.832, \sigma=3.263$.

Given the number of EURO5 vehicles that were tested, the impact of mileage can be analyzed by comparing the PN EF CDF of 4 mileage categories: below $50000 \mathrm{~km}$, between 50000 and $100000 \mathrm{~km}$, between 100000 and $150000 \mathrm{~km}$ and finally above $150000 \mathrm{~km}$ (see Figure 8). For this analysis, EURO5a and EURO5b vehicles will be combined into EURO5, since the goal is to compare the experimental data to the HBEFA degradation factor and increase the number of data per mileage category. The error bars represent the $95 \%$ confidence interval. Even though the confidence intervals are larger compared to those of the entire EURO5 fleet (due

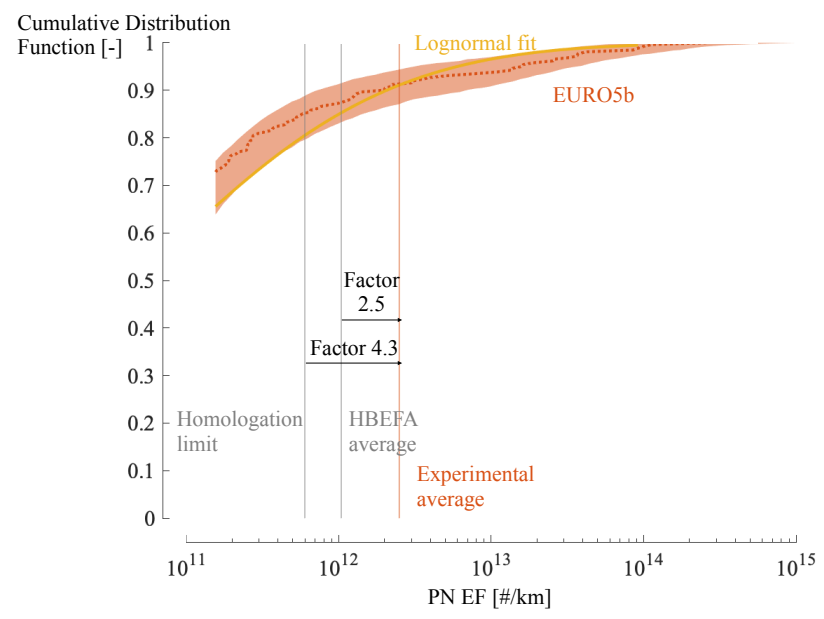

Figure 7: Cumulative distribution function of the computed PN EF (\#/km) for the EURO5b diesel passenger cars. Lognormal fit parameters: $\mu=24.598, \sigma=2.932$.

\begin{tabular}{|c|c|c|}
\hline & \multicolumn{2}{|c|}{$\begin{array}{c}\text { Particle Number } \\
\text { Emission Factor }[\# / \mathrm{km}]\end{array}$} \\
\hline & EURO5a & EURO5b \\
\hline HBEFA Urban & \multicolumn{2}{|c|}{$1.38 \times 10^{12}$} \\
\hline HBEFA Rural & \multicolumn{2}{|c|}{$9.30 \times 10^{11}$} \\
\hline HBEFA Motorway & \multicolumn{2}{|c|}{$8.12 \times 10^{11}$} \\
\hline HBEFA Average & \multicolumn{2}{|c|}{$1.04 \times 10^{12}$} \\
\hline Homologation limit & NA & $6 \times 10^{11}$ \\
\hline Experimental & $5.79 \times 10^{12}$ & $2.60 \times 10^{12}$ \\
\hline
\end{tabular}

Table 5

HBEFA PN EF [14], homologation limit and experimental arithmetic average for the EURO5a and EURO5b diesel vehicles.

to the lower number of vehicles per mileage category), it can be observed that mileage has a significant impact on the PN EF: the arithmetic average emission factor for vehicles having a mileage higher than $150000 \mathrm{~km}$ is 4.4 times higher compared to vehicles with a mileage below $50000 \mathrm{~km}$.

On top of the base emission factor that were discussed above, the HBEFA also provides emission factors that take into account the impact of mileage (up to $250000 \mathrm{~km}$ ), related to the German fleet in 2018. Considering this mileage degradation, the original PN EF (provided in Table 5) are increased by $0.6 \%, 5.1 \%$ and $10.2 \%$ for the urban, rural and highway driving conditions respectively, which results in an increase of $4.4 \%$ for the arithmetic average PN EF [14]. Considering that the tested vehicles with a mileage below 50000 $\mathrm{km}$ represent the HBEFA figure without degradation, the PN $\mathrm{EF}$ of these low-mileage vehicles (i.e. $1.62 \times 10^{12} \mathrm{\#} / \mathrm{km}$ ) is very close to the HBEFA figure (i.e. $1.04 \times 10^{12} \# / \mathrm{km}$ ). On the other hand, when considering the entire fleet which includes some very high emitting vehicles, the experimental arithmetic average reaches $4.47 \times 10^{12} \# / \mathrm{km}$ while the HBEFA PN EF considering mileage degradation is only equal 372 to $1.09 \times 10^{12} \# / \mathrm{km}$. Based on these observations, it seems that the degradation of the emission performance is strongly 
Impact of Mileage on Particle Number Emission Factors for EURO5 and EURO6 Diesel Passenger Cars

underestimated by the HBEFA emission factors.

A similar analysis was not made for EURO6 vehicles since only 128 vehicles were tested, $74 \%$ of them having a mileage below $100000 \mathrm{~km}$. Nevertheless, the PN at low idle measurements for EURO6 vehicles, together with EURO5a and EURO5b, are shown in Figures 9 and 10 with respect to age and mileage.

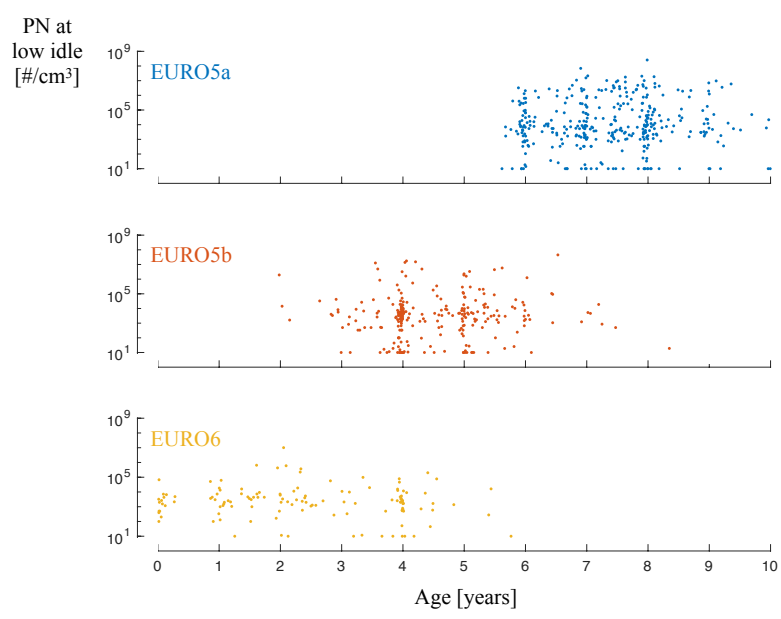

Figure 9: $P N$ at low idle as a function of age for EURO5a, EURO5b and EURO6 vehicles.

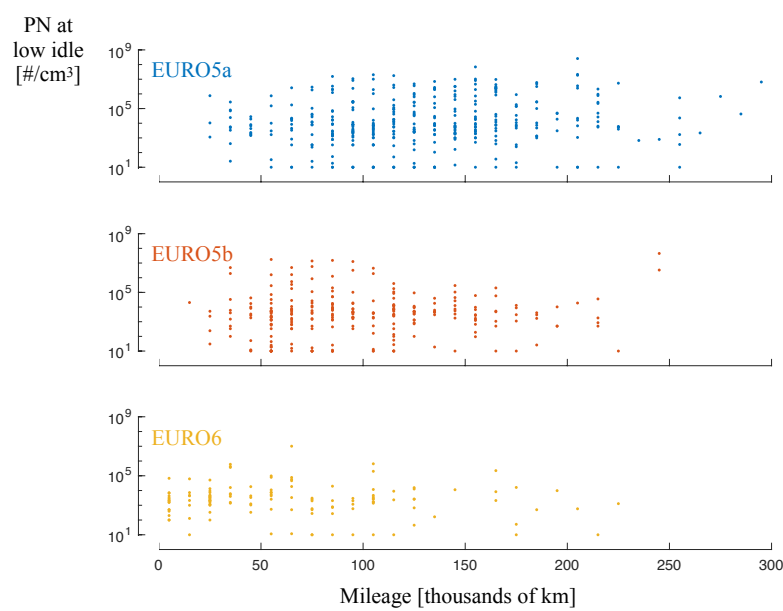

Figure 10: PN at low idle as a function of mileage for EURO5a, EURO5b and EURO6 vehicles.

Regarding the EURO6 vehicles, the CDF of the PN EF is shifted upwards compared to the EURO5 vehicles, meaning that this whole group of vehicles is characterized by lower emissions (see Figure 11). This can mainly be explained by the fact that EURO5 vehicles are older and have higher mileage which increases their emissions. Also, engine-out PN emissions might have been reduced for EURO6 vehicles together with improvements in DPF design and manufacturing processes. In the case of EURO6 diesel vehicles, the arithmetic average HBEFA PN EF (i.e. $1.39 \times 10^{11} \# / \mathrm{km}$ ) is $77 \%$ below the homologation limit (i.e. $6 \times 10^{11} \# / \mathrm{km}$, see Table 6). The gaps between the estimated PN EF (i.e.

\begin{tabular}{|c|c|}
\hline & $\begin{array}{c}\text { Particle Number } \\
\text { Emission Factor }[\# / \mathrm{km}]\end{array}$ \\
\hline HBEFA Urban & $1.36 \times 10^{11}$ \\
\hline HBEFA Rural & $1.03 \times 10^{11}$ \\
\hline HBEFA Motorway & $1.77 \times 10^{11}$ \\
\hline HBEFA Average & $1.39 \times 10^{11}$ \\
\hline Homologation limit & $6 \times 10^{11}$ \\
\hline Experimental & $7.58 \times 10^{11}$ \\
\hline
\end{tabular}

Table 6

HBEFA PN EF for EURO6a and EURO6b vehicles (123 out of the 128 EURO6 vehicles are EURO6a or EURO6b) [14], homologation limit and experimental average for the EURO6 diesel vehicles.

$7.58 \times 10^{11} \# / \mathrm{km}$, computed from low idle PN measurements using the correlation) and the HBEFA and homologation figures are reduced compared to EURO5: the HBEFA and the homologation figures underestimate the estimated PN EF by factors equal to 5.5 and 1.3, respectively. In the case of EURO6 vehicles, it is difficult to analyze the effect of mileage due to the lower number of tested vehicles (128 EURO6 compared to 629 EURO5 vehicles).

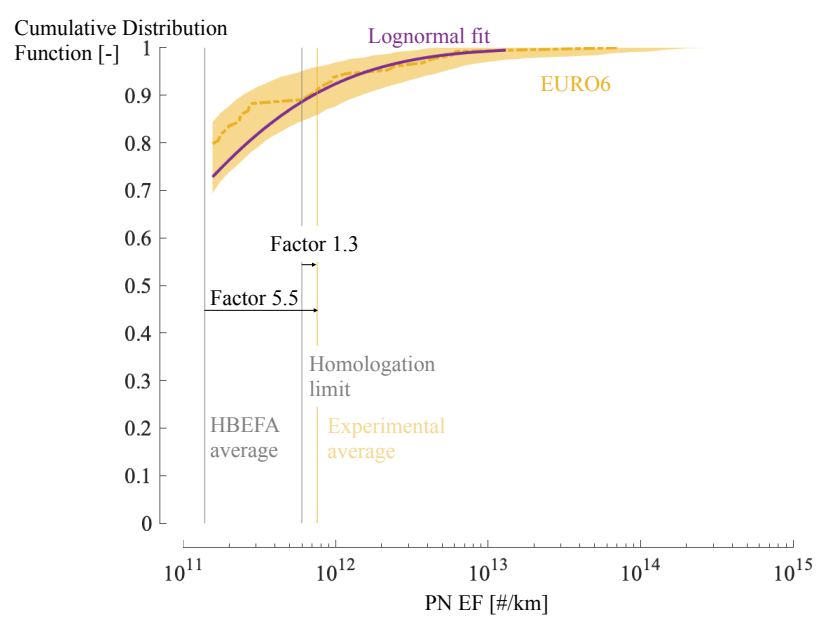

Figure 11: Cumulative distribution function of the computed PN EF $(\# / \mathrm{km})$ for the EURO6 diesel passenger cars. Lognormal fit parameters: $\mu=24.406, \sigma=2.250$.

\section{Conclusion}

This work provides PN emission factor distributions for EURO5a, EURO5b and EURO6 diesel passenger cars based on the measurements of 757 vehicles. The measurements performed on this large fleet consist of measuring the PN concentration at low idle, which shows high correlation with PN emission factors that would be obtained during expensive and time consuming homologation cycles. The vehicles were tested during their Periodic Technical Inspection, which allows to collect additional information such as the mileage of the vehicle, information that is not always available when performing remote sensing measurements for example. 
These distributions show that the majority of the vehicles are clean and have emission factors, estimated from the $\mathrm{PN}$ at low idle measurement and the correlation, below the homologation limit (introduced with the EURO5b emission standard) of $6 \times 10^{11} \# / \mathrm{km}$ (i.e. $68 \%$ of the EURO5a, $85 \%$ of the EURO5b and $89 \%$ of the EURO6 vehicles). Nevertheless, they also show the presence of high emitters of particulate matter which have a dramatic impact on the arithmetic average PN emission factors of the fleet. For the EURO5a vehicles, the high emitters induce a severe increase of the observed experimental arithmetic average (i.e. $5.79 \times 10^{12} \# / \mathrm{km}$ ), estimated from the PN at low idle measurements, which is higher by a factor 5.6 compared to the HBEFA figure. This can be explained by the mileage degradation effect and by the presence of vehicles with very high mileage within this vehicle category. For the EURO5b vehicles, the estimated PN EF (i.e. $2.60 \times 10^{12} \# / \mathrm{km}$ ) is higher than the homologation limit and the HBEFA figure by a factor 4.3 and 2.5 , respectively. Regarding the EURO6 vehicles, the experimental arithmetic average (i.e. $7.58 \times 10^{11} \# / \mathrm{km}$ ) is higher by a factor 1.3 compared to the homologation limit and by a factor 5.5 compared to the HBEFA figure. Because of the significant impact of the high emitters, the sampling of the vehicles is of utmost importance and a large fleet is required to increase the representativeness of the sample and to capture the effect of the high emitters. Therefore, more EURO6 vehicles should be tested to validate the obtained distributions.

Using distributions to characterize the PN emission factors allows to clearly observe the presence of high emitters among the fleet, and removing these high emitters should be the priority when it comes to reducing the emissions of a certain fleet. Also, these distributions and their confidence intervals could be used as input for emission inventories to assess more carefully the impact of the road transport sector for a specific region, by taking the uncertainties into account. Indeed, the emission factors for emission inventories could be modelled as lognormal distributions, which represent the experimental distributions with high fidelity.

Future work could collect data from a larger number of EURO6 vehicles to analyse the influence of mileage for this emission standard. Also, the fitted log-normal distributions could be tuned to match a specific national fleet and then used in the emission models to take into account the variability of the PN emission factors among the fleet.

\section{References}

[1] Abraham, S., Raisee, M., Ghorbaniasl, G., Contino, F., and Lacor, C. (2017). A robust and efficient stepwise regression method for building sparse polynomial chaos expansions. Journal of Computational Physics, 332(3):461-474.

[2] Adèr, H. J., J., M. G., and Hand, D. J. (2008). Advising on research methods: A consultant's companion. Johannes van Kessel Publishing, Huizen, The Netherlands.

[3] Andersson, J., Banks, A., Hansen, B., Jackson, N., Johnson, A., Keenan, M., Mortimer, P., Obaid, B., Osborne, R., Parrett, M., Powell, N., and Sellers, R. (2018). Expectations for actual euro 6 vehicle emissions. Technical Report RD18-000697-2, Ricardo.

[4] Boveroux, F., Cassiers, S., Buekenhoudt, P., Chavatte, L., De Meyer, P., Jeanmart, H., Verhelst, S., and Contino, F. (2019). Feasibility study of a new test procedure to identify high emitters of particulate matter during periodic technical inspection. SAE Technical Paper, 2019-01-1190.

[5] Commission, E. (2017). Commission regulation (eu) 2017/1154 of 7 june 2017 amending regulation (eu) 2017/1151 supplementing regulation (ec) no 715/2007 of the european parliament and of the council on type-approval of motor vehicles with respect to emissions from light passenger and commercial vehicles (euro 5 and euro 6) and on access to vehicle repair and maintenance information, amending directive 2007/46/ec of the european parliament and of the council, commission regulation (ec) no 692/2008 and commission regulation (eu) no 1230/2012 and repealing regulation (ec) no 692/2008 and directive 2007/46/ec of the european parliament and of the council as regards realdriving emissions from light passenger and commercial vehicles (euro 6). Official Journal of the European Union, L 175:708-732.

[6] Emission Analytics (2018). Cutting pollution and improving public health.

https://www. emissionsanalytics.com/news/can-driving-styles-provethe-smarter-route-to-better-fuel-economy-and-emissions-pybwb. Accessed 14th November 2019.

[7] Giechaskiel, B., Bonnel, P., Perujo, A., and Dilara, P. (2019). Solid particle number (spn) portable emissions measurement systems (pems) in the european legislation: A review. Int. J. Environ. Res. Public Health, 16(23):4819.

[8] Giechaskiel, B., Lahde, T., Suarez-Bertoa, R., Clairotte, M., Grigoratos, T., Zardini, A., Perujo, A., and Martini, G. (2018). Particle number measurements in the european legislation and future jrc activities. Combustion Engines, 174(3):3-16.

[9] Guerreiro, C., Colette, A., de Leeuw, F., and González Ortiz, A. (2018). Air quality in europe - 2018 report. Technical report, European Environment Agency (EEA).

[10] Kadijk, G., Elstgeest, M., Ligterink, N. E., and van der Mark, P. J. (2017). Investigation into a periodic technical inspection (pti) test method to check for presence and proper functioning of diesel particulate filters in light-duty diesel vehicles - part 2. Technical Report R10530$1.0, \mathrm{TNO}$

[11] Keller, M., Hausberger, S., Matzer, C., Wüthrich, P., and Notter, B. (2017). Hbefa version 3.3 - backgroup documentation. Technical report, HEBFA, Bern, Switzerland.

[12] Kouridis, C., Gkatzoflias, D., Kioutsioukis, I., Ntziachristos, L., Pastorello, C., and Dilara, P. (2010). Uncertainty estimates and guidance for road transport emission calculations. Technical Report JRC57352, Joint Research Center (JRC), Luxembourg.

[13] Li, N., Georas, S., Alexis, N., Fritz, P., Xia, T., Williams, M. A., Horner, E., and Nel, A. (2016). A work group report on ultrafine particles (american academy of allergy, asthma \& immunology): Why ambient ultrafine and engineered nanoparticles should receive special attention for possible adverse health outcomes in human subjects. Journal of Allergy and Clinical Immunology, 138(2):386-396.

[14] Matzer, C., Weller, K., Dippold, M., Lipp, S., Röck, M., Rexeis, M., and Hausberger, S. (2019). Update of emission factors for hbefa version 4.1. Technical Report Final report, I-05/19/CM EM-I-16/26/679, TU Graz.

[15] Paasonen, P., Kupiainen, K., Klimont, Z., Visschedijk, A., Denier van der Gon, H. A. C., and Amann, M. (2016). Continental anthropogenic primary particle number emissions. Atmospheric Chemistry and Physics, 16:6823-6840.

[16] Riccobono, F., Giechaskiel, B., and Mendoza Villafuerte, P. (2016). Particle number pems inter-laboratory comparison exercise. Publications Office of the European Union, EUR 28136 EN.

[17] TNO, editor (2016). Emission Factors from Emission Measurements - VERSIT+ Methodology. TNO.

[18] Valverde, V., Adrià Mora, B., Clairotte, M., Pavlovic, J., SuarezBertoa, R., Giechaskiel, B., Astorga-LLorens, C., and Fontaras, G. (2019). Emission factors derived from 13 euro $6 \mathrm{~b}$ light-duty vehicles based on laboratory and on-road measurements. Atmosphere, 10,243. 


\begin{tabular}{|c||c|c|c|c||c|}
\hline \multicolumn{1}{|c||}{$\begin{array}{c}\text { Age } \\
\text { [years] }\end{array}$} & \multicolumn{4}{c|}{ Mileage [thousands of km] } & Total \\
\hline \hline $0-2$ & 45 & $50-100$ & $100-150$ & $>150$ & \\
\hline $2-4$ & 12 & 26 & 13 & 7 & 58 \\
\hline $4-6$ & 1 & 6 & 7 & 3 & 17 \\
\hline \hline Total & 58 & 37 & 22 & 11 & 128 \\
\hline
\end{tabular}

Table 4

Mileage and age distribution for EURO6 vehicles.

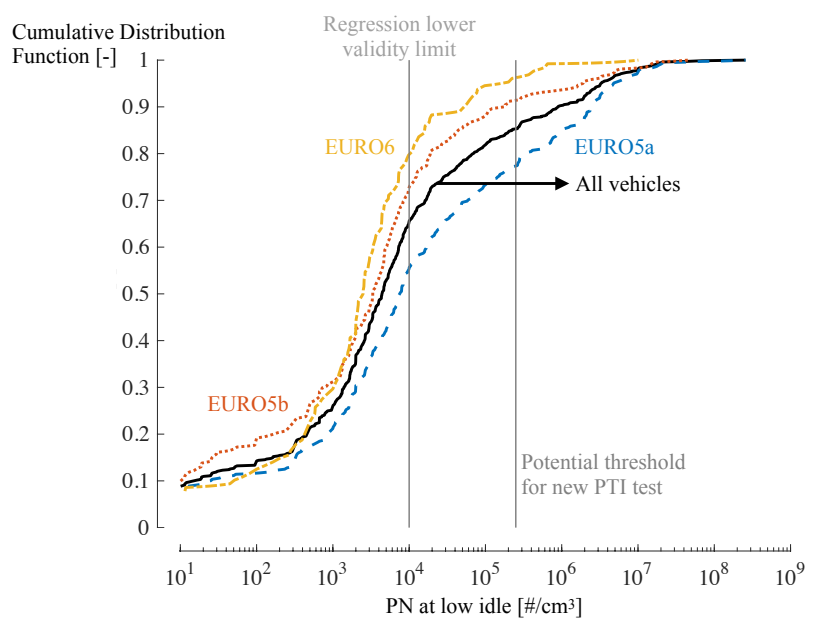

Figure 4: Cumulative distribution function of the PN measurements performed at low idle $\left(\# / \mathrm{cm}^{3}\right)$ of the all the tested vehicles but also for each individual EURO class.

Cumulative Distribution Function [-] 1

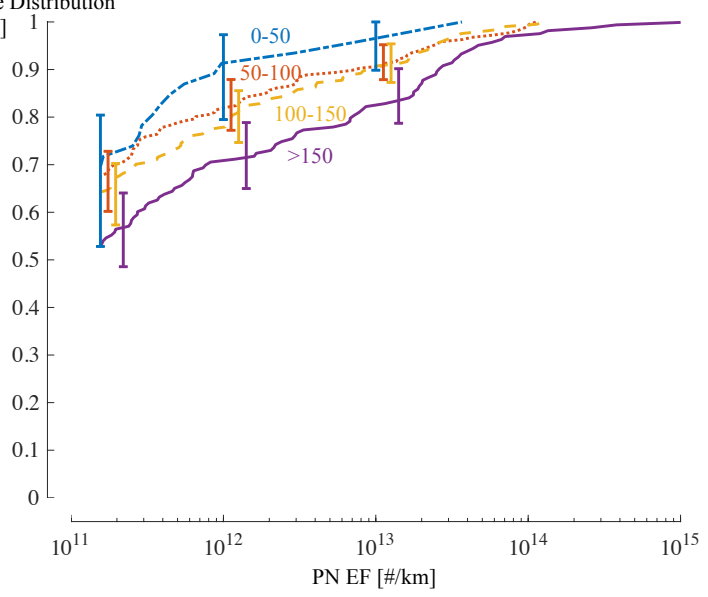

Figure 8: Cumulative distribution function of the computed PN EF $(\# / \mathrm{km})$ for the EURO5 diesel passenger cars for 4 different mileage categories. The mileage categories are identical to the ones used in Tables 2 and 3 and the legends on the graph are expressed in thousands of kilometers. 